\title{
RAPID TOXICOCHEMICAL ANALYSIS IN PHOSPHIDE INTOXICATION CASES
}

\author{
Georgi Bonchev' ${ }^{1}$, Marieta Yovcheva ${ }^{2}$, Sneja Zlateva ${ }^{2}$, Petko Marinov², Vaska Apostolova ${ }^{2}$ \\ ${ }^{1}$ Laboratory of Analytical Toxicology, Military Medical Academy, Naval Hospital - Varna \\ ${ }^{2}$ Clinic of Intensive Treatment of Acute Intoxications and Toxicoallergies, \\ Military Medical Academy, Naval Hospital - Varna
}

\begin{abstract}
In recent years, phosphine and metal phosphides intoxications have been observed extremely rarely in clinical practice. Although rare, these intoxications have a severe clinical course, often with unclear clinical presentation at the beginning and possible lethal exit during the first hours or the next several days. Several tests for analysis of phosphide intoxication, based on the classical qualitative semimicroanalysis which do not require complex equipment, are presented and compared in this article. These tests contribute significantly to confirming the toxicology diagnosis and identifying the source. A rapid paper test (adopting the method of Chugh et al.) has been developed for the purposes of the routine toxicology practice to serve the practicing doctor as quick and exact diagnostic orientation in cases with unclear history and clinical presentation of the intoxication.
\end{abstract}

Keywords: phosphine, phosphides, zinc phosphide

\section{INTRODUCTION}

Phosphides are mainly binary compounds of phosphorus and more electroposititive chemical elements, therefore they can be considered, even if only formally, as salts of phosphine, $\mathrm{PH}_{3}$. Phosphides cannot be found in nature but for some very rare exceptions. They find application as semiconductors (1) and rodenticides (chemicals, used to kill rodents rats, mice, beavers, squirrels, etc.) $(2,3)$. Their significance for clinical toxicology is connected to rodenticide poisonings.

\footnotetext{
Address for correspondence:

Georgi Bonchev

Laboratory of Analytical Toxicology

Naval Hospital - Varna

3 Hristo Smirnenski Blvd

9000, Varna

e-mail: toxilab.varna@abv.bg
}

Received: April 15, 2016

Accepted: November 28, 2016
The following classes of rodenticides are known:

$\diamond$ Anticoagulants - indandiones, chromenone (coumarines) and thiochromenone derivatives;

$\diamond$ Hypercalciemics - calciferol (Vit. D), ergocalciferol (Vit. $\mathrm{D}_{2}$ ) and cholecalciferol (Vit. $\mathrm{D}_{3}$ );

$\diamond$ Phosphides - zinc phosphide $\left(\mathrm{Zn}_{3} \mathrm{P}_{2}\right)$, aluminium phosphide (AlP), magnesium phosphide $\left(\mathrm{Mg}_{3} \mathrm{P}_{2}\right)$

$\diamond$ Others - single compounds like arsenic (III) oxide $\left(\mathrm{As}_{2} \mathrm{O}_{3}\right.$, ,arsenic“), thallium (I) chloride $(\mathrm{TlCl})$, sodium fluoroacetate $\left(\mathrm{F}-\mathrm{CH}_{2}-\mathrm{COONa}\right.$, "1080"), fluoroacetamide $\left(\mathrm{F}-\mathrm{CH}_{2}-\mathrm{CONH}_{2}\right)$, strychnine and variety of other compounds.

Among these classes, nowadays the anticoagulants have the biggest and increasing importance because of their signicant effectiveness against rodents and low toxic risk for humans. The application of phosphides has been increasingly restricted, and as a result almost no phosphide poisonings are observed anymore. But as practice teaches us, although very 
rarely, single cases can be observed. Metal phosphide intoxications are highly risky as they are characterized by sighificant lethality. The lethal dose of ingested metal phosphide (for instance, aluminium phosphide) for a $70 \mathrm{~kg}$ person is estimated to be $150-500$ $\mathrm{mg}$ for a period of 1 to 96 hours, 28 hours in average (11). That is why any laboratory of analytical toxicology should keep a protocol of qualitative analysis of phosphides for emergency cases.

The aim of the study was to make a summary of the accessible fragmented information of chemical methods of approach to identification of phosphides in substances and biological samples.

\section{MATERIALS AND METHODS}

A male patient (M.C.R.), 43 years old, admitted at the Clinic of Intensive Treatment of Acute Intoxications and Toxicoallergies, Naval Hospital Varna, on the 10th of January 2016, on the occasion of ingestion of unknown amount of vodka and an unspecified quantity of dark grey powder (probably rat poison) dusted on a slice of bread, with suicidal purpose. The beginning of the incident was about one hour before the admittance, when his relatives observed vomiting and a generalized convulsion that ended spontaneously, but was followed by several apneic pauses. After that the patient regained consciousness.

The following samples were examined: the rests of the dark grey powder (about $200 \mathrm{mg}$ ) in a nonoriginal plastic package, stomach contents (from the stomach lavage), blood and urine tests of the patient taken at the admittance.

All the used chemical reagents were p.f.a. grade or better. The necessary dilutions were prepared with purified deionized water $(0.067-0.10 \mu \mathrm{S} / \mathrm{cm}$, TKA"Pacific water purification system).

\section{RESULTS}

Chemical analysis of phosphides gives best results if done on available substance of the presumable ingested poison. When such substance is available it is almost always in sufficient amount and the analysis can be done days or weeks after the incident. When no substance is available, satisfactory results can be obtained from the analysis of stomach contents, lavage waters and/or exhaled air by the patient within the time frame of several hours after the intoxication. In all cases the laboratory procedures should be done in a fume hood because the phosphine obtained in the course of the analysis is a poisonous gas, spontaneously flammable in air. Symptoms of intoxication are observed at phosphine concentration in the air of about 35 ppm (4), and the value of $50 \mathrm{ppm}$ (5) is accepted as IDLH limit (immediately dangerous to life or health). As in the human organism the phosphine undergoes a cascade oxidation towards the final product - phosphate, the blood analysis as a whole is non-informative. The analysis of urine does not give reliable results, although in theory following of the concentrations of the intermediate oxidative products (hypophospite and phosphite) is possible (8).

1. Processing the available substance. The patient's information was about "black rat poison". As the clinical presentation was corresponding to this information, it was suggested that the substance contained a metal phosphide. Our task was to prove this and to specify the kind of phosphide. The first landmark is the color of the substance. In this particular case a little plastic container was brought that contained remains (about $200 \mathrm{mg}$ ) of fine black powder, corresponding to zinc phosphide. The white to light grey color of the powder points to aluminum or magnesium phosphide. Next step: a very small amount of the substance, as big as a pinhead, was transferred to a dry test tube for semimicroanalysis and $1 \mathrm{~mL}$ distilled water was added. No reaction was observed, which was again an indication of presence of zinc phosphide. Both aluminum and magnesium phosphides readily react with water. Very carefully, drop by drop, $1 \mathrm{~mL} 5 \% \mathrm{H}_{2} \mathrm{SO}_{4}$ was added, with strict observation of the reaction rate. The present phosphide began to decompose, releasing small bubbles of gas - phosphine:

$\mathrm{Zn}_{3} \mathrm{P}_{2}+3 \mathrm{H}_{2} \mathrm{SO}_{4} \rightarrow 3 \mathrm{ZnSO}_{4}+2 \mathrm{PH}_{3} \uparrow$

Chemically pure phosphine is a colorless and odorless gas, but practically, the produced technicalgrade phosphine had a characteristic odor because of contaminations (faint scent, sweetish, garlic-like, resembling rotten fish) that can be felt even at very 
low concentrations - under $0.5 \mathrm{ppm}$ (7), i.e. under the immediate health risk limits. The liberated from the test tube phosphine was proven by the following analytical reactions:

1.1. Iodine test. A filter paper soaked with one drop of diluted water solution of iodine gradually decolorized:

$\mathrm{PH}_{3}+2 \mathrm{I}_{2}+2 \mathrm{H}_{2} \mathrm{O} \rightarrow \mathrm{H}_{3} \mathrm{PO}_{2}+4 \mathrm{HI}$

Analogically, the phosphine can decolorize bromine water as well. In this case the oxidation goes further to phosphoric acid:

$$
\mathrm{PH}_{3}+4 \mathrm{Br}_{2}+4 \mathrm{H}_{2} \mathrm{O} \rightarrow \mathrm{H}_{3} \mathrm{PO}_{4}+8 \mathrm{HBr}
$$

1.2. Permanganate test. A filter paper soaked with one drop diluted water solution of $\mathrm{KMnO}_{4}$ is slowly decolorized. In acidic solutions (1 drop of $5 \% \mathrm{H}_{2} \mathrm{SO}_{4}$ ) the decolorization is full (reduction to $\mathrm{Mn}^{2+}$ ), while in neutral solutions the purple color of the permanganate turns into yellowish-brown (reduction to $\mathrm{Mn}^{4+}$ ).

1.3. Silver nitrate test. A filter paper soaked with one drop of $10 \% \mathrm{AgNO}_{3}$ becomes black: $8 \mathrm{Ag} \downarrow$

$3 \mathrm{AgNO}_{3}+\mathrm{PH}_{3} \rightarrow 3 \mathrm{HNO}_{3}+\mathrm{Ag}_{3} \mathrm{P} \downarrow$

$8 \mathrm{AgNO}_{3}+\mathrm{PH}_{3}+4 \mathrm{H}_{2} \mathrm{O} \rightarrow 8 \mathrm{HNO}_{3}+\mathrm{H}_{3} \mathrm{PO}_{4}+$

This test is very sensitive and gives immediate results even at very low phosphine concentration. It can be done either with moist or dry filter paper. When the phosphine is in great quantities the metal glitter of the produced silver can be noticed. However, it is necessary first to exclude the possibility of blackening due to hydrogen sulfide (i.e., due to the presence of sulfides in the original substance). This can be done by an additional test with filter paper soaked with one drop of $10 \% \mathrm{~Pb}\left(\mathrm{CH}_{3} \mathrm{COO}\right)_{2}$ - it becomes black only in the presence of hydrogen sulfide. This test was negative in the described particular case, which was evidence of lack of hydrogen sulfide and a final proof of released phosphine. In case of positive lead acetate test however, the presence of phosphine should be proved by a more profound analysis using the next two steps $(1.4,1.5)$.

1.4. Molybdate test. The blackened filter paper from the silver nitrate test (1.3) is processed further with the aim to prove the produced phosphoric acid. One drop of $50 \% \mathrm{HNO}_{3}$ is applied on the black spot immediately followed by one drop of saturated water solution of ammonium molybdate. At the boundaries of the wet spot yellow coloration appears gradually:

$\mathrm{H}_{3} \mathrm{PO}_{4}+12\left(\mathrm{NH}_{4}\right)_{2} \mathrm{MoO}_{4}+21 \mathrm{HNO}_{3} \rightarrow 21$ $\mathrm{NH}_{4} \mathrm{NO}_{3}+12 \mathrm{H}_{2} \mathrm{O}+\left(\mathrm{NH}_{4}\right)_{3} \mathrm{PMo}_{12} \mathrm{O}_{40} \downarrow$

For additional certainty, one could process further by adding water solution of a reducing agent, for instance - ascorbic acid or sodium sulphite. In this process the yellow coloration gradually turns into blue ("molybdenum blue") and because of mixing of the colors a transition from yellow to green to blue is observed. This method is sensitive and selective but requires an exact stoichiometry that is difficult to achieve in practice, that is why its realization is capricious and negative results are not simple to interpret. On the contrary, the positive result here is always definitive. In the described particular case the molybdate test was positive.

1.5. The alternative of the method described above is the following scheme: the blackened filter paper from the silver nitrate test (1.3) is covered by calcium hypochlorite powder and is left to stay for 15 minutes in moist atmosphere (oxidation of the phosphite to phosphate). The excess of hypochlorite is removed mechanically and by washing away with small amount of water. Test strip is dried carefully using filter paper or clean paper serviette. One drop of molybdenum liquid is added $(35 \mathrm{~mL}$ concentrated nitric acid, $1.42 \mathrm{~g} \mathrm{~cm}^{-1}$, is added to a solution of 5 g ammonia molybdate in $100 \mathrm{~mL}$ distilled water) followed by one drop of toluidine reactive $(50 \mathrm{mg} \mathrm{o}$ toluidine is mixed with $10 \mathrm{~mL}$ glacial acetic acid and the mixture is diluted to $100 \mathrm{~mL}$ with distilled water). The processed paper is exposed for a few minutes to the effect of ammonia vapors in a stain jar, containing a few milliliters of concentrated ammonia solution $\left(0.88 \mathrm{~g} \mathrm{~cm}^{-3}\right)$. The appearance of blue coloration is considered a definite proof of phosphine.

At this stage the main task is accomplished: a presence of phosphide has been proved. The remaining goal is to analyze its cationic part. From a practical viewpoint the expected possibilities are few: $\mathrm{Mg}^{2+}, \mathrm{Zn}^{2+}$, and $\mathrm{Al}^{3+}$.

1.6. The investigation continues with the rest of the solution, produced during the dissolving of the original substance in sulfuric acid. This solution has been filtrated under normal pressure using filter paper (Whatman, blue ribbon) and 1-2 $\mathrm{mL}$ 
Georgi Bonchev, Marieta Yovcheva, Sneja Zlateva et all.

colorless crystal clear solution has been produced. The liquid is divided into two portions and to each of them carefully, drop by drop, $1 \mathrm{M} \mathrm{NaOH}$ is added, until cloudy white gel is formed. This precipitate is characteristic for all of magnesium, zinc, and aluminum ions: $\mathrm{x}=2,3)$

$$
\mathrm{Me}^{\mathrm{x}+}+\mathrm{x} \mathrm{OH}^{-} \rightarrow \mathrm{Me}(\mathrm{OH})_{\mathrm{x}} \downarrow \quad(\mathrm{Me}=\mathrm{Mg}, \mathrm{Zn}, \mathrm{Al} ;
$$

1.7. An excess of $\mathrm{NaOH}$ solution is added to the first portion of precipitate. If the precipitate is not dissolved, this is an indication of the presence of magnesium: magnesium phosphide, $\mathrm{Mg}_{3} \mathrm{P}_{2}$, is proven in the initial substance. In the described particular case, however, the sediment was dissolved, and this rejects the possibility of magnesium presence:

$$
\begin{aligned}
& \mathrm{Zn}(\mathrm{OH})_{2}+2 \mathrm{OH}^{-} \rightarrow\left[\mathrm{Zn}(\mathrm{OH})_{4}\right]^{2-} \\
& \mathrm{Al}(\mathrm{OH})_{3}+3 \mathrm{OH}^{-} \rightarrow\left[\mathrm{Al}(\mathrm{OH})_{6}\right]^{3-}
\end{aligned}
$$

1.8. An excess of concentrated solution of ammonia was added to the second portion. If the precipitate is not dissolved, that is an indication of the presence of aluminum: aluminum phosphide, AlP, is proved in the initial substance. In the particular described case, however, the sediment was dissolved:

$$
\mathrm{Zn}(\mathrm{OH})_{2}+4 \mathrm{NH}_{3} \rightarrow\left[\mathrm{Zn}\left(\mathrm{NH}_{3}\right)_{4}\right](\mathrm{OH})_{2}
$$

This way the possibility of aluminum presence is rejected. Analysis of the original substance gives the final conclusion that zinc phosphide, $\mathrm{Zn}_{3} \mathrm{P}_{2}$, is present, which confirms the initial observations.

During the work on the particular described case, an additional clarification was done. In principle, chemical producers add up to $25 \%$ antimonyl potassium tartrate ("emetic tartar"), $\mathrm{K}_{2} \mathrm{Sb}_{2}\left(\mathrm{C}_{4} \mathrm{H}_{2} \mathrm{O}_{6}\right)_{2}$ to rodenticide formulations for the mass consumer. The potent emetic action of this supplement on people limits the risk of involuntary or intentional intoxication, while the rodenticide's effectiveness is not impaired, because rodents lack emetic reflex (6). The presence of such supplement in the studied substance can be proven by the following procedures:

1.9. One $\mathrm{mL}$ of hot water is poured over several milligrams of the original substance, and stirred. A clear solution is taken (by filtering, centrifuging or decanting) and is divided into three portions.

$1 \mathrm{M} \mathrm{NaOH}$ is added drop by drop to one of the portions. In case of a positive test, a white, amphoteric precipitate is formed:

\section{$\mathrm{Sb}^{3+}+3 \mathrm{OH}^{-} \rightarrow \mathrm{HSbO}_{2} \downarrow+\mathrm{H}_{2} \mathrm{O}$}

$10 \% \mathrm{AgNO}_{3}$ is added to second portion. In case of positive test, white precipitate of silver tartrate is observed.

$10 \% \mathrm{~Pb}\left(\mathrm{CH}_{3} \mathrm{COO}\right)_{2}$ is added to the last portion. In case of a positive test, white precipitate of lead tartrate is observed.

During the work in this particular case, none of these reactions gave a positive result, so the presence of antimonyl potassium tartrate in the original substance was rejected. This was an indication that the available substance was more likely to be of industrial origin, and was not designed for the common consumer.

2. Processing biological material. It is necessary for the confirmation of the diagnosis, especially in cases when the ingested substance is not available for investigation. The lavage waters and the stomach content are subject to chemical analysis. The procedure is analogical to the described in the previous section, but it is advisable to do only the most sensitive of the reported steps (the silver nitrate test and perhaps the molybdate test) because of the low concentration of the phosphides. First, 5-10 mL of the examined fluid are acidified with $1-2 \mathrm{~mL} 20 \% \mathrm{H}_{2} \mathrm{SO}_{4}$ in a test tube, then heated to $50^{\circ} \mathrm{C}$ using a water bath. The paper soaked with silver nitrate is put in front of the opening of the test tube. The result is read within 20 minutes: the test is positive if a clearly formed greyish-black spot can be observed. The test for hydrogen sulfide is obligatory in this case, as the probability of its presence in biological materials cannot be neglected.

3. Processing exhaled air. The metal phosphides that have entered in the acidic medium of the stomach are actively hydrolyzed, and the released phosphine is exhaled, beginning several minutes and lasting up to several hours after the intoxication. That is why it is possible in such cases to detect the specific smell of the phosphine in the exhaled air. However, this subjective method does not possess adequate reliability. In combined intoxications with alcohol, as is the described 
case, the odor of phosphine can be masked out and not identified. Therefore, it is necessary to prove the phosphine in the exhaled air by chemical analysis. This can be done with filter paper impregnated with $0.1 \mathrm{M} \mathrm{AgNO}_{3}$ as suggested by some authors $(9,10)$. The dried paper is put so to cover the patient's mouth, and if it is possible, let him breathe through it. A layer of gauze is put in order to avoid direct contact with the silver salt and the black coloration of the skin that the salt may cause. In case of a positive result, after several minutes a dark spot is formed (grey to black color, depending on the severity of the intoxication and the time that has passed after the incident).

\section{DISCUSSION}

The described case is a confirmation of the fact that in toxicology practice we can meet pesticides, rodenticides or other highly toxic compounds that have been withdrawn from use long ago. In many private homes there are rodenticides past the expiry date, but nevertheless they remain toxic. The summary of the accessible chemical methods for analysis showed a significant fragmentariness of the information, contradictory directions and unconvincing reliability. This makes the choice of method for routine application uncertain. That is why with this study the known and available methods have been arranged in a clear algorithm, convenient for the practice of laboratory of analytical toxicology, especially in case of emergency.

Express indicator strips has been developed on a paper carrier by adopting the method of Chugh et al. (9). Paper strips were made, ready for use, which should be present in every toxicological emergency room and can be easily used by the doctor who has first met the intoxicated patient. In cases when there is no contact with the patient, and no information can be received from him/her or the relatives, the placing of a paper indicator strip in front of the patient's mouth could prove or reject the presence of phosphine intoxication within several minutes.

\section{CONCLUSIONS}

The present study actualizes and summarizes the available chemical methods of proving phosphorus (phosphine, phosphides) in substances, material evidence and biological fluids, for the purposes of clinical toxicology practice. The study has contributed to the adoption of an express test on a paper carrier (indicator strips) for demonstration of phosphorus (phosphine) presence in exhaled air. This is an undisputable contribution to facilitation of the clinical toxicologist's work in cases with unclear intoxication.

\section{REFERENCES}

1. Sharon M, Tamizhmani G. Transition metal phosphide semiconductors for their possible use in photoelectrochemical cells and solar chargeable battery. J. of Mat. Sci. 1986;21(6):2193-201

2. Chitty D, Southern H. Control of rats and mice, Vol. 1. London: Oxford University Press; 1954. p. 305

3. Schoof HF. Zinc phosphide as a rodenticide. Pest Control. 1970;38(5):42-4

4. Jones AT, Jones RC, Longley EO. Environmental and clinical aspects of bulk wheat fumigation with aluminum phosphide. Am. Ind. Hyg. Assoc. J. 1964;23:375-9

5. Tab. Biol. Per. Berlin. 1933;(3):231 (in German)

6. Fox J, Anderson L, Loew F, Quimby F. Laboratory Animal Medicine. 2nd ed. New York: Academic Press; 2002

7. Amoore JE, Hautala E. Odor as an aid to chemical safety: odor thresholds compared with threshold limit values and volatilities for 214 industrial chemicals in air and water dilution. J. Appl. Toxicol. 1983;3(6):272-90

8. World Health Organization. Phosphine and selected metalphosphides, IPCS. Environmental Health Criteria. WHO: Geneva; 1988(73)

9. Chugh SN, Ram S, Chugh K, Malhotra KC. Spot diagnosis of aluminium phosphide ingestion: an application of a simple test. J. Assoc. Physicians India. 1989;37(3):219-20

10. Wahab A, Zaheer MS, Wahab S, Khan RA. Acute aluminium phosphide poisoning: an update. Hong Kong J. Emerg. Med. 2008;15:152-5

11. Koreti S, Verma YS, Prasad N, Patel GS, Rajput $\mathrm{N}$. Aluminium phosphide poisoning in children -challenges in diagnosis and management. Sch. Acad. J. Biosci. 2014;2(8):505-9 